\title{
Elderly African Americans Insights on the COVID-19 Pandemic: An Exploratory Study of Risk Perception and Personal, Social, and Cultural Factors
}

\author{
Osei K. Darkwa, John Holton \\ Jane Addams College of Social Work, University of Illinois-Chicago, Chicago, IL, USA \\ Email:darkwa@uic.edu,jkholton@uic.edu
}

How to cite this paper: Darkwa, O.K. and Holton, J. (2021) Elderly African Americans Insights on the COVID-19 Pandemic: An Exploratory Study of Risk Perception and Personal, Social, and Cultural Factors. Health, 13, 354-368.

https://doi.org/10.4236/health.2021.134029

Received: March 8, 2021

Accepted: April 6, 2021

Published: April 9, 2021

Copyright $\odot 2021$ by author(s) and Scientific Research Publishing Inc. This work is licensed under the Creative Commons Attribution International License (CC BY 4.0).

http://creativecommons.org/licenses/by/4.0/

\section{(c) (i) Open Access}

\begin{abstract}
This exploratory study examined elderly African Americans attitudes on the COVID-19 pandemic by identifying their perceptions of risk based personal, social, and cultural factors. It seeks to understand their insights toward public health pandemic response initiatives and other efforts to mitigate COVID-19 outbreak response measures impacting elderly African Americans, including policies, interventions, and public information/communication. The effectiveness of pandemic response measures and community caregiving support for the elderly African Americans was examined as well. Respondents in this study were a convenient sample of 60 residents predominantly in a Midwestern metropolitan area. Respondents were eligible for study participation if 1) there were 60 years and over and, 2) African American or people of African descent. A mixed research method design comprising focus groups and online survey was used to collect the data for the study. The respondents characterized the impact of the coronavirus as a personal, family, and community loss (e.g., less socially engaged and burdensome). An overwhelming majority (98.3\%) expressed no worries about getting health care if they or their family members needed it. A sizable number of respondents expressed the need for all to be tested to help prevent the spread of the virus.
\end{abstract}

\section{Keywords}

COVID-19, Elderly African Americans, Risk Perception, Symptoms of the Coronavirus, Attitude toward Testing, Health Care Experience

\section{Project Description and Summary}

COVID-19, a twenty-first century global pandemic, has spread to every state in 
the United States including the District of Columbia. The pandemic has changed our way of life and experts have labelled it the most crucial global health calamity of the century and the greatest challenge that the humankind faced since World War II. COVID-19 will be recorded as not only one of the most pressing issues of our time, but also as an occurrence which has most acutely highlighted the fault lines in our society. What started as a regional health crisis in late 2019 had, by March of 2020 grown into a global pandemic never seen for a century.

Information continues to unfold about the short and long-term impact of the virus, its transmission, prevalence, mortality and overall impact. By the end of August 2020, the US had about 6,096,410 COVID-19 infections; of this number, over 184,962 had died and epidemiological models were projecting a doubling of the deaths before year end [1] [2]. Experts believe that the numbers represent only the tip of the iceberg since the figures exclude asymptomatic carriers in the population [3].

Available evidence confirms that older adults and people who have severe underlying medical conditions such as diabetes, heart or lung disease, are the most severely impacted age cohort by COVID-19. According to the World Health Organization [2], although people of all ages can be infected by COVID-19, older adults and individuals with pre-existing medical conditions who are more vulnerable and most likely to become severely ill. As of mid-April, $31 \%$ of the nation's cases, $45 \%$ of hospitalizations, $53 \%$ of ICU admissions, and $80 \%$ of deaths associated with COVID-19 had occurred among adults aged 65 years and older, with the highest percentage of deaths occurring among persons older than 85 years [2]. According to the Center for Disease Control and Prevention [4], 8 out of 10 COVID-19-related deaths reported in the United States have been among adults aged 65 years and older with the majority over 85 years of age [4].

Available information points to the fact that communities of color have suffered disproportionately from the impact of COVID-19. For example, while African Americans make up 30 percent of the population in Chicago, they account for 68 percent COVID-19 deaths [5], also, in the District of Columbia where Blacks make up $45 \%$ of the total population, $59 \%$ of deaths as of April 5, 2020. Additionally, in Louisiana, while Blacks constitute $32 \%$ of the total state population, they account for over 70\% of COVID-19 cases as of April 6, 2020 [6]. Research has found similar disparate trends in cities such as Charlotte, North Carolina, St. Louis, New York, Birmingham Alabama, Milwaukee, Grand Rapids Michigan, New Orleans and other locations [7] [8] [9]. The current research depicts that COVID-19 reported death rates in all these cities tend to be higher among African Americans compared to their white counterparts.

Research by the Center for Disease Control [4] has found that African Americans have the highest rates of COVID-19 related deaths compared to whites as well as among the nation's classified racial/ethnic groups (American Indians, 
Hispanic, and Asians).

Extant multiple health challenges overlap psycho-social realities among the African American population, including a lack of health insurance, suspicion of the health care system, and economic and social factors have been cited as factors contributing to the disproportionate rate of COVID-19 infection among this population [10] [11]. According to U.S. Surgeon General, Jerome Adams, people of color are not "biologically or genetically predisposed to get COVID-19," but socially predisposed to coronavirus exposure."

\section{Research Objectives and Questions}

This exploratory study examined elderly African Americans attitudes about the COVID-19 pandemic by identifying their perceptions of risk based personal, social, and cultural factors. It seeks to understand their insights toward public health pandemic response initiatives and other efforts to mitigate COVID-19 outbreak response measures impacting elderly African Americans, including policies, interventions, and public information/communication. In essence, this study explored the African American response to being described as the "most likely to die" from COVID-19. Conversely, the effectiveness of pandemic response measures and community caregiving support for the elderly African Americans was examined as well.

The specific research questions posed by the study are the following:

1) To examine the impact, risk perceptions, knowledge, self-efficacy from the insights of elderly African Americans on their COVID-19 experience.

2) To examine the health-related factors and the health care experiences among elderly African American in a pandemic era, and

3) To identify how social distancing requirements impact the care and well-being of elderly African American.

\section{Project Rationale and Significance}

There is anecdotal evidence, supported by medical record data, to depict that the coronavirus is disproportionately affecting communities of color, especially African Americans than their white counterparts. This has been attributed to a number of factors, among the prominent ones are 1) the existence of pre-existing conditions that tend to disproportionately affect the African American community; 2) inequalities inherent within the health care system that are influenced by implicit bias and racial discrimination; and 3) the overrepresentation of African Americans in essential jobs.

While these factors have been mentioned, there is little empirical evidence to support the perceptions of high, and therefore adverse, COVID-19 infection rates among elderly African Americans. For example, researchers such as Myers [11] and Dyer [10] have studied racial difference in COVID-19 infection but this has been from the perspective of the general minority population, not the older African American population. Understanding the COVID-19 experience of Af- 
rican Americans will allow health care officials and policy makers to assist such communities in managing the pandemic among the older adult population, thereby reducing mortality rates, and saving lives.

\section{Study Methodology}

\subsection{Study Design}

Respondents in this study were a convenient sample of 66 residents predominantly in a Midwestern metropolitan area. Respondents were eligible for study participation if 1) there were 60 years and over and, 2) African American or people of African descent.

Two African American churches (Westside and Southside) were recruited to assist in the identification of the sample. Traditionally, the church has played a central role in the lives of African Americans. Previous research has indicated that African-Americans benefit physically, psychologically, and socially when they are involved with religious organizations [12]. Religion and religious institutions have assisted African-Americans both materially and psychologically [13] [14] [15] [16]. And research has consistently highlighted the importance of the African-American church for individuals, couples, and families. The two collaborating institutions (churches) are a place where a sizable number of the potential study sample (elderly African Americans, 60 and over) worship. This community happens to be one of the communities badly affected by COVID-19. Thus, the selection of the two sites assisted the study investigators in reaching out to the sample most of whom live in the community. The churches assisted in distributing information about the study to their congregants.

\subsection{Ethical Approval (Protocol \# 2020-0734)}

The Office of Protection of Research Subjects (OPRS) of the university approved the study protocol, procedures, information sheet and consent statement by a review committee on the protection of human subjects in early July 2020. This gave the researchers the green light to commence the study which was carried out from May 2020 through August 2020.

\subsection{Data Collection}

A mixed research method design comprising focus groups and online survey was used to collect the data for the study. One graduate research assistant was employed to coordinate the data collection with the collaborating churches. It took an average of 40 - 45 minutes to complete the questionnaire which had two parts-qualitative (focus groups) and quantitative (survey) questions. Even though the study targeted 50 respondents, 56 respondents completed the online survey while 10 completed the manual (hard copy) questionnaire. Some of the questionnaires were poorly completed. Due to this, they were exempted from the analysis. Eventually, questionnaires from 56 respondents were used as the basis 
of analysis for the study.

\subsection{Study Instrument}

The survey instrument used is an adaptation of the COVID-19 Impact on Health and Wellbeing Survey and a combination of other instruments. The questionnaire consisted of six main themes: 1) health concerns which asked questions about access to health care, health status, and risk factors in contracting the coronavirus; 2) knowledge about COVID-19; 3) perceived risks and attitudes toward COVID-19; and 4) mitigation measures and practices relevant to COVID-19, 5) sources of information about COVID-19, and 6) sociodemographic profile of respondents

\subsection{Measures}

The research was conducted to examine risk perceptions, knowledge, self-efficacy from the insights of elderly African Americans on their COVID-19 experience, examine the health-related factors and the health care experiences among elderly African American in a pandemic era, and to identify how social distancing requirements impact the care and well-being of elderly African American.

To solicit in-depth information about risk perceptions, knowledge, and self-efficacy, respondents were asked open-ended questions and were requested to narrate their experiences about the coronavirus and what they perceive to be the signs and symptoms of the virus, and how the pandemic had affected their lives. Additional close ended questions were asked to ascertain their knowledge about the virus, symptoms, transmission mode, sources of information about the virus, its spread, and measures being taken to protect themselves. We designed a Likert five-point scale from "Hardly effective to Very Effective" to capture measures.

To solicit in-depth information about health-related factors, respondents were asked open-ended questions about how the health care system has helped or hindered their health care needs, how their healthcare has been affected by the virus, and what they do to protect themselves against being infected by the virus. Additional survey questions (closed ended) were asked about their health care needs, factors that place them at risks for contracting the virus, their health and insurance status.

Regarding how social distancing requirements impact the care and well-being of respondents were asked questions pertaining to place of residence, household composition, home ownership, household income, source of income, and zip code.

\subsection{Statistical Analysis}

Most of the respondents completed the online version of the survey instrument in Google Form. The software aggregated the data in Google Sheets. This was later exported to Microsoft Excel and to the Statistical Package for the Social Sciences (SPSS). Since this is a pilot study, most of the analysis was descriptive, 
focusing on frequencies and percentages. This level of analysis was enough to respond to the key research questions posed by the study.

\subsection{Demographic Data of the Sample}

Of the 56 participants who responded to our questions surrounding demographics, 52 respondents (approximately 94\%) identified themselves as African American or Black of African Origin, with one respondent indicating 'other' and 2 respondents inputting no entry. The present study had 33 female respondents (58.9\%) and 23 male respondents (41.1\%), with one participant declining to respond to the question on gender.

Regarding the age profile, majority of participants fell between 65 - 74 years in age (47\%), with just under one fourth of the participants aged at 75 and older (24\%) and the remaining portion of participants aged between 55 - 64 years old (29\%).

Education level for participants ranged widely with the majority of participants education level being graduate degree (33\%); about one fourth of participants having a professional degree (25\%); and remaining degree levels varied amongst bachelor's degree (11\%), associate degree (11\%), some college but no degree (13\%), and high school graduate (7\%). Over half of the participants were married or partnered (53\%), with just over one third (35\%) being separated, divorced, or widowed.

Approximately two-thirds of the sample were retired (67\%), with other third being employed (29\%), unable to work due to disability or unemployed $(3 \%)$. The present sample main sources of income were through employment (24\%), social security (35\%), and other sources (31\%), with the remaining saying their income source is from social security or disability funds.

Family income ranged from below $\$ 20,000$ (9\%) to $\$ 100,000$ and over (16\%).

Religion plays a major role among the respondents. A slight majority of participants indicated that their religious denominations were Protestant (33\%), predominantly followed by Presbyterian and Methodist (24\%), other denominations (27\%), or no denomination (16\%).

Nearly all of the 56 respondents live in Illinois (93\%), with only four respondents residing in other states being California, Florida, Virginia, and Alabama. Over half (55\%) of the participants live in a home composed of $2-3$ individuals, with household compositions consisting of children, spouses, siblings, and other family members. Table 1 presents details about the socio-demographic profile of the respondents.

\section{Findings}

\subsection{Risk Perceptions, Knowledge, Self-Efficacy from the Insights of Elderly African Americans on Their COVID-19 Experience}

When asked how respondents rate their knowledge level on how to prevent the spread of the virus, an overwhelming majority, $84.8 \%$ rated their knowledge as either good or very good on preventive measures. The majority (over $80 \%$ ) identified 
Table 1. Demographic data of the sample.

\begin{tabular}{|c|c|c|}
\hline Racial Background $n=55$ & Freq & $\%$ \\
\hline African American & 48 & $87.3 \%$ \\
\hline Black of African Origin & 6 & $10.9 \%$ \\
\hline Other & 1 & $0.08 \%$ \\
\hline Total & 55 & $100 \%$ \\
\hline Gender $n=56$ & Freq & $\%$ \\
\hline Female & 33 & $58.9 \%$ \\
\hline Male & 23 & $41.1 \%$ \\
\hline Total & 56 & $100 \%$ \\
\hline Age in Years $(n=56)$ & $\mathbf{N}$ & $\%$ \\
\hline $55-64$ & 16 & $28.6 \%$ \\
\hline $65-74$ & 26 & $48.2 \%$ \\
\hline 75 and older & 13 & $23.2 \%$ \\
\hline Education Level $n=55$ & Freq & $\%$ \\
\hline Less than high school degree & 0 & $0.00 \%$ \\
\hline High school graduate (high school diploma or equivalent including GED) & 4 & $7.27 \%$ \\
\hline Some college but no degree & 7 & $12.73 \%$ \\
\hline Associate degree & 6 & $10.91 \%$ \\
\hline Bachelor's degree & 6 & $10.91 \%$ \\
\hline Graduate school & 18 & $32.73 \%$ \\
\hline Professional degree (JD, MD, etc.) & 14 & $25.45 \%$ \\
\hline Marital Status $(\mathrm{n}=55)$ & $\mathbf{N}$ & $\%$ \\
\hline Married & 28 & $50.91 \%$ \\
\hline Widowed & 7 & $12.73 \%$ \\
\hline Divorced & 10 & $18.18 \%$ \\
\hline Separated & 2 & $3.64 \%$ \\
\hline Single & 7 & $12.73 \%$ \\
\hline Partnered & 1 & $1.82 \%$ \\
\hline Work Status $(n=56)$ & $\mathrm{N}$ & $\%$ \\
\hline Retired & 37 & $66.1 \%$ \\
\hline Working (part-time) & 5 & $8.9 \%$ \\
\hline Working (full-time) & 11 & $21.4 \%$ \\
\hline Unemployed before the virus & 1 & $1.82 \%$ \\
\hline Not working due to disability & 1 & $1.82 \%$ \\
\hline Family Income (in thousands) $(\mathrm{n}=55)$ & Freq & $\%$ \\
\hline$\$ 10,000-\$ 19,000$ & 5 & $9.09 \%$ \\
\hline$\$ 20,000-\$ 29,000$ & 5 & $9.09 \%$ \\
\hline
\end{tabular}




\begin{tabular}{ccc}
\hline$\$ 30,000-\$ 39,000$ & 3 & $5.45 \%$ \\
$\$ 40,000-\$ 49,000$ & 4 & $7.27 \%$ \\
$\$ 50,000-\$ 59,000$ & 6 & $10.91 \%$ \\
$\$ 60,000-\$ 69,000$ & 7 & $12.73 \%$ \\
$\$ 70,000-\$ 79,000$ & 3 & $5.45 \%$ \\
$\$ 80,000-\$ 89,000$ & 6 & $10.91 \%$ \\
$\$ 90,000-\$ 99,000$ & 3 & $5.45 \%$ \\
$\$ 100,000$ and over & 9 & $16.36 \%$ \\
\hline Type of Housing (n = 55) & $\mathbf{N}$ & $\%$ \\
\hline House/Condo/Townhouse & 48 & $87.27 \%$ \\
Apartment & 7 & $12.73 \%$ \\
Transitional Housing & 0 & $0.00 \%$ \\
Other & 0 & $0.00 \%$ \\
\hline Rent or own residence (n=55) & $\mathbf{N}$ & $\%$ \\
\hline Rent & 12 & $21.82 \%$ \\
Own & 43 & $78.18 \%$ \\
\hline & & \\
\hline
\end{tabular}

Table 2. Provides a summary of key responses to risk perception and knowledge about the coronavirus.

\begin{tabular}{ccc}
\hline $\begin{array}{c}\text { How would you rate your knowledge level on how to } \\
\text { prevent the spread of the Coronavirus }(\mathbf{N}=53)\end{array}$ & N & $\%$ \\
\hline Very poor knowledge & 0 & 0 \\
Poor & 0 & 0 \\
Fair & 7 & 13.2 \\
Good & 12 & 22.6 \\
Very Good & 34 & 64.2 \\
Total & 53 & 100 \\
\hline
\end{tabular}

sore throat, fever, running nose, fatigue, loss of appetite, vomiting, nausea, diarrhea, dizziness, loss of ability to taste and smell as symptoms of the coronavirus.

When asked how they will rate their knowledge about COVID-19, a majority, 86.8\% rated their knowledge as either good or very good (Table 2).

Regarding the mode of virus transmission, an overwhelming majority (90\%) indicated channels such as having close contact with an infected person who has symptoms, having close contact with an infected person not showing symptoms, and contact with surfaces an infected person has touched.

When asked about the most effective actions for keeping safe from the coronavirus, majority of the respondents (over 50\%) indicated a) wearing a face mask, praying, seeing a health care provider, avoiding public gatherings and crowds, and avoiding public transport as the top reasons to keep safe from the 
virus infection.

Regarding measures they themselves have taken to prevent infection from the virus, over $70 \%$ indicated hand washing, staying home, self-isolation as the top reasons to avoid infection.

The respondents when asked to express the impact of the coronavirus has affected their lives in general in an open ended question, most of them provided reasons such as 1) reduced income, 2) loss of employment, loss of freedom, 3) become more introverted, because [I] do not want to risk becoming infected, 4) limited freedom like not being able to see some relatives and church members, and 5) adherence to wearing protective face masks and gloves, washing of hands and constant reminders to sanitize my hands.

\subsection{Health-Related Factors and the Health Care Experiences among elderly African American in a Pandemic Era}

An overwhelming majority (98.3\%) expressed no worries about getting health care if they or their family members needed it. It is only $15.8 \%$ who expressed worry about their health needs while $8.8 \%$ indicated they were not sure. When asked if they have factors that place them at high risk for contracting the coronavirus, an overwhelming majority (64.9\%) indicated in the affirmative. It was only $39.6 \%$ who indicated they are not at high risk, with a small majority indicating they are not sure. However, when asked if someone living with them have risk factors for contracting the coronavirus, the majority of respondents (54.4\%) indicated none did while $42.1 \%$ responded in the affirmative, with a small minority indicating they were not sure.

Co-morbidity is one of the factors identified as predisposing the elderly to COVID-19 infection. When asked about their co-morbidity status, $52.7 \%$ indicated they have chronic illness while $41.8 \%$ indicated they do not have such a challenge. When asked the type of chronic illness, the top three were diabetes, hypertension, and high blood pressure.

When asked if they have been infected with the coronavirus, an overwhelming majority (89.5\%) responded in the negative. Only a very small percent (3\%) responded they've been infected with the coronavirus. Again, when asked if anyone in their household was self-isolating due to a suspected coronavirus, an overwhelming majority $(91.2 \%)$ responded in the negative. Only $7 \%$ said maybe.

Regarding insurance status, an overwhelming majority (98.2\%) indicated they have health insurance. When asked an open-ended question regarding how the health care system has helped or hindered their health care needs with the outbreak of the virus, most of them expressed inability to physically visit their doctor as the biggest concern. Most of them prefer physical visit instead of the virtual appointment with health care providers. Some see virtual visits as a poor replacement for in-person visits. However, most of them expressed satisfaction with the kind of insurance they have which has made it possible to continue to receive the best of health care. Others expressed their appreciation to their doctor for periodically checking on them (Table 3). 
Table 3. Provides a summary response to a number of health-related issues.

\begin{tabular}{|c|c|c|}
\hline $\begin{array}{l}\text { Are you worried about getting health care if you or any of } \\
\text { your family member needs it }(\mathrm{N}=53)\end{array}$ & $\mathrm{N}$ & $\%$ \\
\hline Yes & 8.4 & 15.8 \\
\hline No & 40.0 & 75.4 \\
\hline Not sure & 4.6 & 8.8 \\
\hline Total & 53 & 100 \\
\hline $\begin{array}{l}\text { Do you have risk factors that place you at high risk for } \\
\text { contracting the Coronavirus }(\mathrm{N}=57)\end{array}$ & $\mathbf{N}$ & $\%$ \\
\hline Yes & 37 & 64.9 \\
\hline No & 18 & 31.6 \\
\hline Not sure & 2 & 3.5 \\
\hline Total & 57 & 100 \\
\hline Do you have chronic illness $(\mathrm{N}=55)$ & $\mathbf{N}$ & $\%$ \\
\hline Yes & 29 & 52.7 \\
\hline No & 23 & 41.8 \\
\hline Don’t know & 3 & 5.5 \\
\hline Total & 55 & 100 \\
\hline Do you have any kind of health insurance $(\mathrm{N}=57)$ & $\mathbf{N}$ & $\%$ \\
\hline Yes & 56 & 98.2 \\
\hline No & 1 & 7.8 \\
\hline Total & 57 & 100 \\
\hline
\end{tabular}

\subsection{Family Support, Household Structure, Testing and Social Distancing Requirements}

Regarding housing status, the majority of participants reside in a house/condo/ townhouse $(87 \%)$ with all other participants residing in an apartment (13\%). Over three fourths $(78 \%)$ of participants own their place of residence while the remaining participants (22\%) rent their residence.

Regarding household composition, 32.1\% indicated they live alone, while $55.4 \%$ indicated they live with one or two additional persons. When asked who lives with them, the majority of respondents indicated they live with their spouse, only a handful indicated they live with other family members.

When asked an open-ended question how family members have assisted them during the coronavirus outbreak, most of them indicated that their family members provide all their grocery needs, to prevent them from going out, use mask, practice physical distancing, use hand sanitizer and healthy hygiene habits, communicate with family frequently, on a daily basis, Overall, family members have been very supportive and available and closer to family members than before.

Most of the respondents expressed the fact that the silver linen for them during this pandemic has been innovation in doing things, having family members 
around, spending more time with spouse and taking care of the house, the opportunity to sit, mediate, commune with God and see the beauty in God's handiwork, spending more time in prayer and spiritual uplift, explore the use of technology by spending more time with friends virtually.

One of the tools used to control the spread of the pandemic is testing and contact tracing. A sizable number of respondents expressed the need for all to be tested to help prevent the spread of the virus. Some even expressed the need for testing and contact tracing to be mandatory to assist people in knowing their coronavirus status. They expressed the need for testing to be available for all who need it, symptoms or no symptoms and it should either be free or covered by insurance.

\section{Discussion of Findings}

Research on the impact of COVID-19 is still in its infant stages, given the fact that the pandemic was detected in December 2019. Few researchers have undertaken studies to examine knowledge, attitudes and practices toward COVID-19. While most of the studies have focused on the general population, only a limited number of studies have examined the knowledge and impact of the coronavirus on communities of color. In spite of this limitation, certain findings in this pilot study confirm and add to current knowledge about elderly African Americans insights on the COVID-19 pandemic.

With regard to the risk perceptions, knowledge, self-efficacy from the insights of elderly African Americans on their COVID-19 experience, an overwhelming majority are knowledgeable about what to do to prevent themselves from contracting the coronavirus. The majority are aware of the symptoms of the virus. Also, a greater majority are aware of the mode of transmission of the virus. Praying to God is one factor mentioned by a sizable number of the respondents as a tool in coping with the pandemic. This finding is consistent with the literature on African Americans and the impact of spirituality (prayer) and religion in their lives. The literature depicts consistently the high level of religious involvement among African Americans generally and, elderly African American in particular [17] [18]. The latter finding was expected given the fact that the majority of the respondents are affiliated with a faith-based institution. Religion is used as a coping mechanism among this population to overcome life challenges; it is consistent with the history of African American churches serving as a pillar during challenging times.

The corona virus has impacted this population and has affected their income sources in the form of reduced income, employment status, freedom of movement, and social activities.

Regarding the impact of health-related factors, an overwhelming majority expressed no worries about getting health care if they or their family members needed it. Most respondents have some form of medical insurance, an important factor in health care access.

More than half of the sample indicated they had at least one chronic illness. 
Thus, co-morbidity was prevalent among the sample. The three top illnesses were hypertension, diabetes, and high blood pressure. These findings are consistent with the literature which reports that about $66 \%$ of people aged 70 and over have at least one underlying condition [19] [20] [21]. This makes them susceptible and places them at increased risk of contracting COVID-19.

Respondents reported no self-isolating behaviours at home. This could be to the small number of persons living at home and the high sociodemographic profile of the respondents. Most of them were high income earners living on social security and other types of investment.

While most respondents prefer to see their health care provider or physician physically, this was not possible given the challenges posed by the pandemic. For most of the respondents, this was a major hindrance. However, since most of them were covered by some form of insurance, this made it possible for them to continue to receive health care, albeit at a distance. Respondents expressed gratitude to their physicians who periodically called to check on their welfare and wellbeing.

Regarding family support, household structure and social distancing, the study found that an overwhelming majority of the respondents resided in their own homes with only a small group residing in apartments. The high-income level, residential arrangement and limited household composition provided a layer of protection against been infected with the coronavirus. This explains why majority of the respondents felt they were less likely to contract the coronavirus, a finding consistent with the literature. In a study by the Pew Research Center titled "Health Concerns from COVID-19 Much higher Among Hispanics and Blacks than Whites", the study found that while most Americans are concerned they may contract COVID-19, a concern much more widespread among black and Hispanic adults than white, they found difference in concerns across income levels. While a third of Americans with lower incomes (regardless of race) expressed concern about contracting the virus, only about half (17\%) of upper-income adults expressed such concern [22].

The presence of a spouse in over $40 \%$ of the households provided additional social support in a pandemic era.

Family members continue to play an instrumental role in the upkeep of respondents. This is consistent with the literature on family supportive services of African Americans [23]. Family were always ready to address both Activities of Daily Living and Instrumental Activities of Daily Living.

The existence of the virus has not been inherently negative. It has unleased the creativity and innovation among some of the respondents. Some of them indicated they now get to spend more time with spouse, commune more with their maker, and learn new technological skills.

\section{Conclusions and Recommendations}

While limited in sample size and the type of sampling type (convenient sample), 
the study was able to examine the impact, risk perceptions, knowledge, self-efficacy from the insights of older adult African Americans on their COVID-19 experience, and to identify some of the health-related factors and the health care experiences among elderly African American in a pandemic era. The findings suggest a high level of knowledge on COVID-19 among the respondents who feel generally positive in their outlook on dealing with the challenges presented by the pandemic. It raises a number of research issues to be explored in follow up studies, particularly given the family status of older adults as repositories of wisdom, advice, and knowledge about individual and world matters.

There is the need to undertake more studies on the impact of COVID-19 on communities of color and how their pandemic experience affects their' lives compared to their white counterparts.

Testing has been one of the tools being used the world over to ascertain the number of people infected with the virus within a given locality. This has been identified as key to controlling the pandemic. The goal of testing and contact tracing is to mitigate the impact of the pandemic by preventing severe illness and death from the virus. To date, there is little knowledge about the attitude and perception of people toward testing. This is an important factor among communities of color who have a historic mistrust for the health care system. Research is needed to explore attitude and perception toward testing among communities of color.

Most of the respondents indicated how staying at home has brought them closer to other family members through the use of technology such as Zoom, Skype, Facetime, and other multimedia social platforms. Research to explore family connectedness in a pandemic era will go a long way to provide a new dimension on the impact of family connectedness on other forms of family support.

The existence of the virus has not been inherently negative. It has unleased the creativity and innovation among some of the respondents. Some of them indicated that they now get to spend more time with spouse, commune more with their maker, and learn new technological skills.

\section{Author Contribution}

Osei K. Darkwa: Conceptualization, Study significance, Data Collection, Draft Preparation, Reviewing and Editing, Policy Recommendations.

John Holton: Conceptualization, Methodology, Data Collection, Data Validation and Analysis, Writing, Policy Recommendation.

All authors have read and agreed to the published version of the manuscript.

\section{Acknowledgements}

We would like to express our appreciation to the Jane Addams College of Social Work, particularly to Dean Creasie Finney Hairston for making it possible for us to undertake this study. The College provided funding to make this study possible. 


\section{Funding Statement}

This research was supported by a grant from the Jane Addams College of Social Work, University of Illinois-Chicago. The funder had no role in the study design, data collection and analysis, decision to publish, or preparation of the manuscript.

\section{Study Highlights}

- Impact of the coronavirus is viewed as a personal, family, and community loss.

- An overwhelming majority expressed no worries about getting health care if they or their family members needed it.

- The need for all to be tested to help prevent the spread of the virus.

- Respondents pose a high level of knowledge on COVID-19 and feel generally positive in their outlook on dealing with the challenges presented by the pandemic.

- The need for research to explore further family connectedness in a pandemic era.

\section{Conflicts of Interest}

The authors declare no conflicts of interest regarding the publication of this paper.

\section{References}

[1] Worldometer (2020) COVID-19 Coronavirus Pandemic. https://www.worldometers.info/coronavirus/?utm campaign=homeAdvegas1

[2] World Health Organization (2020). https://www.afro.who.int/

[3] Jahromi, A.H. and Hamidianjahroni, A. (2020) Why African Americans Are a Potential Target for COVID-19 Infection in the United States. Journal of Medical Internet Research, 22, e19934. https://doi.org/10.2196/19934

[4] Center for Disease Control and Prevention (2021) Older Adults. https://www.cdc.gov/coronavirus/2019-ncov/need-extra-precautions/older-adults.h $\underline{\mathrm{tml}}$

[5] Illinois Department of Public Health (2020) COVID-19 Statistics. https://www.dph.illinois.gov/covid19/covid19-statistics

[6] Louisiana Department of Health (2020) COVID-19. http://ldh.la.gov/coronavirus

[7] Alabama Public Health (2020) Characteristics of Laboratory-Confirmed Cases of COVID-19. https://www.alabamapublichealth.gov/index.html

[8] Echols F. The St. Louis American (2020) All 12 COVID-19 Deaths in the City of St. Louis Were Black.

http://www.stlamerican.com/your health matters/covid 19/all-12-covid-19-deaths -in-the-city-of-st-louis-were-black/article da7ed56c-79d1-11ea-85bc-7b8539eaf346. html

[9] New York City Health (2020) COVID-19: Data. https://www1.nyc.gov/site/doh/covid/covid-19-data.page 
[10] Dyer, O. (2020) Covid-19: Black People and Other Minorities Are Hardest Hit in US. BMJ, 369, m1483. https://doi.org/10.1136/bmj.m1483

[11] Myers, E. (2020) Compounding Health Risks and Increased Vulnerability to SARS-CoV-2 for Racial and Ethnic Minorities and Low Socioeconomic Status Individuals in the United States. https://www.preprints.org/manuscript/202004.0234/v1

[12] Chaney, C. (2008) The Benefits of Church Involvement for African-Americans: The Perspectives of Congregants, Church Staff, and the Church Pastor. Journal of Religion and Society, 10. https://dspace2.creighton.edu/xmlui/handle/10504/64373

[13] Lincoln, C.E. and Mamiya, L.H. (1990) The Black Church in the African American Experience. Duke University Press, Durham.

[14] Mays, B.E. and Nicholson, J.W. (1933) The Negro's Church. Russell and Russell, New York.

[15] Nelsen, H.M. and Nelsen, A.K. (1975) Black Church in the Sixties. University Press of Kentucky, Lexington.

[16] Nightingale, M. (2003) Religion, Spirituality, and Ethnicity: What It Means for Caregivers of Persons with Alzheimer's Disease and Related Disorders. Dementia, 2, 379-391. https://doi.org/10.1177/14713012030023006

[17] Chatters, L.M. and Taylor, R.J. (1989) Age Differences in Religious Participation among Black Adults. Journal of Gerontology: Social Science, 44, S183-S189. https://doi.org/10.1093/geronj/44.5.S183

[18] Taylor, R. and Chatters, L. (1988) Church Members as a Source of Informal Support. Review of Religious Research, 30, 193-203. https://doi.org/10.2307/3511355

[19] Bonow, R.O., Fonarow, G.C., O’Gara, P.T. and Yancy, C.W. (2020) Association of Coronavirus Disease 2019 (COVID-19) with Myocardial Injury and Mortality. JAMA Cardiology, 5, 751-753. https://doi.org/10.1001/jamacardio.2020.1105

[20] Grasselli, G., Zangrillo, A., Zanella, A., et al. (2020) COVID-19 Lombardy ICU Network. Baseline Characteristics and Outcomes of 1591 Patients Infected with SARS-CoV-2 Admitted to ICUs of the Lombardy Region, Italy. JAMA, 323, 1574-1581. https://doi.org/10.1001/jama.2020.5394

[21] Shi, S., Qin, M., Shen, B., et al. (2020) Association of Cardiac Injury with Mortality in Hospitalized Patients with COVID19 in Wuhan, China. JAMA Cardiology, 5, 802-810. https://doi.org/10.1001/jamacardio.2020.0950

[22] Pew Research Center (2020) Health Concerns from COVID-19 Much Higher among Hispanics and Blacks than Whites.

[23] Chadiha, L.A., Morrow-Howell, N., Darkwa, O. and Berg-Weger, M. (1996) Support Systems of African American Family Caregivers of Elders with Dementing Illness. African American Research Perspectives, 9, 104-114. 